\title{
Efraim Podoksik, Estienne de La Boëtie and the politics of obedience
}

Filippo Fonio

\section{(2) OpenEdition}

1 Journals

Edizione digitale

URL: https://journals.openedition.org/studifrancesi/39143

DOI: 10.4000/studifrancesi.39143

ISSN: 2421-5856

Editore

Rosenberg \& Sellier

\section{Edizione cartacea}

Data di pubblicazione: 1 décembre 2004

Paginazione: $350-351$

ISSN: 0039-2944

\section{Notizia bibliografica digitale}

Filippo Fonio, «Efraim Podoksik, Estienne de La Boëtie and the politics of obedience», Studi Francesi [Online], 143 (XLVIII | II) | 2004, online dal 30 novembre 2015, consultato il 19 mai 2021. URL: http:// journals.openedition.org/studifrancesi/39143 ; DOI: https://doi.org/10.4000/studifrancesi.39143

Questo documento è stato generato automaticamente il 19 mai 2021.

\section{(c) $(7)$}

Studi Francesi è distribuita con Licenza Creative Commons Attribuzione - Non commerciale - Non opere derivate 4.0 Internazionale. 


\title{
Efraim Podoksik, Estienne de La Boëtie and the politics of obedience
}

\author{
Filippo Fonio
}

\section{NOTIZIA}

EFRAIM PODOKSIK, Estienne de La Boëtie and the politics of obedience, "Bibliothèque d'Humanisme et Renaissance", LXV, 1 (2003), pp. 83-95.

1 Il saggio in questione si basa sul raffronto fra le posizioni politiche sottese a due opere di Estienne de La Boëtie, De la Servitude volontaire ou contrun e Memoires sur l'édit de janvier 1562.

2 De la Servitude volontaire doveva essere incluso nel primo volume degli Essais montaignani. Già all'inizio del regno di Henri III il testo circolava largamente, letto come pamphlet antimonarchico dagli ugonotti rivoluzionari. Torna in auge nel 1789, e di nuovo presso marxisti e anarchici. Non si è ancora fatta chiarezza sulla data di composizione e sulle circostanze della prima edizione. Secondo Montaigne si tratta di opera giovanile, ma egli tiene soprattutto a sottolineare che l'amico Estienne de La Boëtie non era un rivoluzionario. È stata anche formulata l'ipotesi che buona parte del testo sia stata scritta da Montaigne stesso. Quanto ai Memoires, considerati perduti, essi furono ritrovati soltanto nel 1917.

Mentre si è per lo più considerato il primo testo alla stregua di un libello antitirannico e libertario, i Memoires sarebbero invece schierati su posizioni più conservatrici, contro la tolleranza religiosa e la legittimazione della confessione riformata, per un ritorno all'ordine al fine di scongiurare ogni rischio di indebolimento dell'autorità regia. Tesi dell'autore è che i Memoires e la scelta dell'obbedienza siano la logica conseguenza delle posizioni espresse nel precedente trattato. La Boëtie e Montaigne sono accomunati da una nozione individualistica della libertà, con pochi riferimenti al bene comune e alla comunità politica. Concetto prossimo a questo di libertà è l'amicizia, anch'essa concepita in un'ottica non collettivista, ma come relazione a carattere privato, e che 
può anche venire in contrasto con i doveri pubblici, ai quali, anti-ciceronianamente, va anteposta. Tali elementi, comuni alle due opere, fungono da base per delineare una posizione anarchica e apolitica di La Boëtie pensatore, ispirata alle nozioni stoica e agostiniana di libertà come condizione naturale (opinione condivisa in seguito da Locke), e caratterizzata da un'importanza primaria attribuita alla pace civile. Il profilo tracciato offre la possibilità di formulare un'ipotesi sulla presunta carica antitirannica del libello De la Servitude volontaire: "The answer is [...] not to engage in active resistance but to withdraw into the realm of the private", p. 93. 